\title{
A FRAME WORK FOR ENHANCING THE USE OF INDIGENOUS KNOWLEDGE SYSTEM IN TECHNOLOGY DEVELOPMENT AND UTILIZATION IN DEVELOPING ECONOMY
}

OGBONNA, KALU IROHA

(Received 21 April 2017; Revision Accepted 7 May 2019)

\begin{abstract}
The productivity of agriculture in Nigeria over the years has relied extensively on the scientific innovations transferred to farmers from research institutes via extension services. Thus, technology development most often has been based on scientific research approach, with little or no collaboration with the indigenous people. This is based on the argument that indigenous people are ignorant, fatalistic and have nothing to offer as solutions to their problems. Incidentally, the imposition of scientific technology development framework, without the incorporation of the indigenous knowledge systems of local communities to a large extent, is believed to have contributed to failures in sustainable resource use and erosion of biodiversity. It is evident that indigenous societies have profound and detailed knowledge of the system, environment and species (plants and animals) which they are in contact with for generations and have developed strategies based on their own indigenous technical knowledge to solve their own problems. Therefore, full recognition of indigenous knowledge system of the "supposed users" of technology, their local traditions and technology endowment capabilities are central to the issue of sustainable and equitable technology development and utilization. This paper examines critically the technology development processes and suggest framework for enhancing the integration and use of indigenous knowledge system in technology development
\end{abstract}

\section{INTRODUDTION}

In many African production systems, researchers have blamed the retrogression in agricultural production particularly food production on non-utilization and nonadoption of modern technology developed from modern scientist knowledge (Tripp 1985). Unfortunately, agricultural production technologies were designed as if all the farm families in Africa share the same economic, social, cultural and ecological conditions. This mistaken assumption has led to technology meant for the rural farmers being designed outside the user's immediate environment, resulting in negative effects on the users. Lack of effective research approach for tackling the complex problems of adapting available technology to the highly diverse conditions of small farmers has been identified as one major reason for non-adoption of scientifically approved technologies, (Ashby, 1998). Inspite of many efforts from both private and public agencies and organizations towards agricultural development, it has been established

A paper presented at the $22^{\text {nd }}$ Annual Congress of the Nigerian Rural Sociological Association held at University of Uyo, uyo, Akwa Ibom State, September, 17-20. that technology development process has been based on scientific research with little or no collaboration with the local people. Rajasekaran (1993) observed that the scientific systems of technology development as commonly used especially in the developed economies, do not really integrate indigenous knowledge system and do not carry along the entire farm firmly as they are based on scientific control processes, which underscores the roles, values and means of integrating local knowledge into technology development. In recent times, many researchers have observed that full recognition of local knowledge system is central to the issue of sustainable development. No society can ever hope to achieve a long term goal of sustainable development unless it builds upon its own knowledge, tradition, ethical foundations and technological endowments,(Gupta,1992). Thus, indigenous knowledge has been found to be very relevant in resource conservation because indigenous societies of the different groups tend to have profound and detained knowledge of the systems and species with which they are in contact with for generations. Indigenous knowledge system which entail knowledge, innovation and practices of indigenous people is unique to a given culture or society because it optimally utilize available

Ogbonna, Kalu Iroha, Department of Agricultural Extension and Rural Sociology University of Calabar, Calabar, Nigeria. 
resources, explores and exploits existing diversities, takes into account the instability of the environment and promote livelihood and sustained use of productive resources, (Warren 1991, Ajibade 1999; Warren, et al 1989).

In recent times, concern towards agricultural and sustainable development have given increasing attention to the question of indigenous knowledge and practices of local people, as well as their participation in the process of development. However, indigenous knowledge which is found to exist in every region in subSaharan Africa is said to be overlooked in development efforts, particularly in the area of technology design and development (Phillps and Titilola 1995). The potential contributions of indigenous knowledge to uplifting the livelihood of the local people notwithstanding, some people still believe that it is backward, conservative, inefficient, inferior and based largely on myths (Kolawole 2001; Titilola 2003). Even though there are ample ethno-scientific information presently, detailing the relevance of the indigenous practices in agriculture within the African continent, indigenous knowledge is still largely ignored by scientists or designers of production technologies. Hence, the technology development approaches utilized over the years have not taken into consideration the unique resource endowment such as ecosystem fragility, skills preferences and knowledge base of society. The wrong notion that the local people especially the non-literate rural dwellers in developing countries, have nothing to offer as solutions to their problems have to a large extent contributed to the neglect of indigenous knowledge systems of the local people in the process of technology development.

The common practice adopted in initiating technology development has remained the researcher or scientist taking full control in developing policies, strategies and methodologies of research, while the indigenous people's initiatives are not sought for or utilized, (Roling and Pretty 1995). Efforts at solving local people's sociocultural problems or addressing the problems of agricultural production have not however systematically involved small farmers as active participants in the planning, execution and evaluation of research. Instead, technology has been designed with little or no consideration of the role of local people's knowledge in the entire processes. Given the fact that local people have continued to use traditional technologies in food production, there is the need to develop strategies capable of tapping or re-trieving their existing knowledge and incorporating same in the development of sustainable production system. . But the pertinent questions that confront us have been: What is the process of technology development commonly adopted by researchers in the sub-Saharan African countries? What is the value of indigenous knowledge in technology development and how can it been harnessed, used and integrated into technology development? It has become necessary therefore for scientists and other development practitioners to harness community-based initiatives through collaborative research, in which activities jointly designed will not only empower communities, but will generate sustainable strategies to conserve local environments and revitalise traditional cultures.

Thus paper is therefore designed to review methods and techniques adopted in technology development with the aims of identifying their short comings; determine the value and relevance of indigenous knowledge and local people's participation in technology development and finally propose a framework for the integration of indigenous knowledge for sustainable agricultural development

\section{MODELS/METHODS/APPROACHES UTILISED IN TECHNOLOGY DEVELOPMENT}

There have been a growing awareness that the socioeconomic and agro-ecological conditions of resourcepoor farmers are complex, diverse and risk-prone and efforts are being focused mostly on increasing the involvement of farmers in technology development and transfer. An enormous variety of methodologies have been developed and used by thousands of professionals over the years in the process of developing technologies. In recent times, a number of approaches and methodologies have been tried and utilised to facilitate farmers participation in technology development and a good numbers researchers have started to apply them. Below is a review of some of the approaches, models or methods tried and utilised in technology development

\section{CONVENTIONAL TECHNOLOGY DEVELOPMENT APPROACH}

In Nigeria and other developing countries before now, scientists, particularly those involved in agricultural matters are trained to view agricultural innovation as a process of vertical transfer by bringing in foreign technologies, adapting and transferring them to farmers. However, the indigenous technical knowledge embodied in farmers experimentation, considered a valuable resources, remain untapped and used in technology development process. The neglect of farmers' expertise is linked to the formal methodological approaches which provide scientists with techniques for conducting and implementing the result of research in ways that do not enable small farmers to utilize their expert knowledge of local conditions, their skills and capacity for self-help. Under this approach the farmer is seen as a user or beneficiary of technology outcomes and has no input in the technology development. Instead, it is the scientists' task to identify, analyse and to solve farmers' technical problems by developing solutions at the research station, without taking into serious considerations the distinctive economic, social and cultural traits of the farm families in different regions and transferring the result as messages to farmers via the extension workers, whose role it is to assist farmers in putting the ready-made technology into practice. In other words, the only linkage between the scientist and the farmer in this process is extension which is the technology transfer medium.

In this model, technology development was based on the development of intellectuals which comprises individuals having formal education in different areas of agricultural technology. These intellectuals formed the 
bases for designing various levels of technologies meant for farmers' utilization. While these scientists are actively involved in the development of the technologies, the farmers on the other hand were regarded as mere recipients of such technologies. The reliance of scientists on this model was based on the assumption that technology developed from scientists' knowledge and delivered to farmers by extension will address the problems of rural area. In other words, this model assumes that farmers' problem can be solved by people and institutions that have the custody of modern knowledge (Anon, 1998). Inadvertently, the intellectual, cultural and social gap between the professional scientists who are confined in experimental stations and the farmers in the rural communities get wider and wider and this makes it difficult for scientists to see how semiliterate, bare-foot farmers can participate in research, and hence voluntarily involve them in the intellectual process of defining problems, setting priorities and identifying potential solutions, (Ashby, 1998)

This model which has been described as top-down, rigid, hierarchical and devoid of feedback, has one obvious disadvantage which is the long time usually required for feedback from farmers to get to scientists and back to them. Thus, these deficiencies associated with this approach employed in the technology development process has been linked to the failure to bring about the desired increase in food production and the adoption of technology by farmers, vis-as-vis sustainable national development (Tripp, 1985). From this argument, it is clear that conventional on-farm research did not institutionalize farmer-scientist collaboration in the planning, testing and evaluation of technologies from the onset. As a result, research activities anchored on these conventional methods and approaches were found to constitute more of a problem than solutions to farmers' needs.

\section{TRANSFER OF TECHNOLOGY (TOT)}

In most developing countries the Transfer of Technology (ToT) model has been common practice for developing and disseminating technologies. In this model, technology knowledge is believed to be generated by research organisations, then transferred by extension services to farmers who utilised them. It is based on the assumption that technologies developed by scientists and transferred to farmers will trigger agricultural development and solve farmers' problems identified by scientists through their varied scientific approaches. The model assumes that while the role of agricultural research institutes and its researchers is to generate knowledge and technologies, the role of extension services in the process is to handle the subsequent dissemination of technologies and to provide a link between researchers, policy makers and farmers. The farmers on their part, rather than being seen as potential initiators of solutions to their problems, are viewed as mere passive receivers of messages transmitted from the research organisations.

Like the past conventional methodologies, this approach disregarded the fact that the majority of small-scale farmers who form the bulk of farm producers in developing countries did not have the same economic resources to embrace technologies developed by scientists. Also, little account was taken of local knowledge and value systems. Thus, the farmers response to the new technical messages developed by scientists and transferred by extension was much less successful than predicted and adoption rates were usually very low. Rather than investigating the reason for farmers passive resistance to technologies developed, a number of researchers rationalised farmers' action as a sign of traditionalism, ignorance and lack of flexibility. Also, farmers who could not accept the technologies from research stations were often labelled by extensions as laggards, who lacked the right attitude and capabilities. This linear top-down flow of information which characterised this model creates a rigid hierarchy that discourages interaction and feedback of information.

The model therefore, does not really provide an opportunity for researchers, extension staff and farmers to work together. Technologies developed under this model tend to be prescriptive and uniform and such technologies do not pay attention to particular environments, conditions, opportunities and local knowledge of the receiving audience. In spite of this, both the scientist and extension conventionally expect unquestioning and universal acceptance of the technologies promoted, from farmers.

\section{FARMING SYSTEM RESEARCH}

With the lapses noticed in the transfer of technology model, a new approach to agricultural research which emphasized participation of farmers in the farming systems research emerged in developing countries in the mid seventies. In this approach, trails were conducted together with farmers to identify the constraints of existing production systems which will lead to the production of new improved technology packages. Under this arrangement, the farmer's role was to provide land and labour, act as an experimental control by farming on an adjacent plot with his standard practices and later respond to the results of the experimental treatments. In this process, the extension worker demonstrate the technologies developed by the scientists on farmers farm for them to observe and see what, why, when and how to carry out the technology packages, while the research scientist provides leadership in designing the research (Baker 1996). In the farming system research approach, extension specifically worked with farmers to identify their problems and with the help of researchers, solutions are found. Although there is some element of participation in the approach, however, the farmer is seen as a passive participant in the technology development, who has no input in whatever form in the development of the technology package. Rather than helping farmers to solve their own problems through direct involvement in the development process, the approach fostered reliance on the extension workers and their resource base to solve the problems identified by the farmer. Also, little account is taken of local knowledge and value systems of benefiting audience. The implication is that the technologies developed by the scientists without the 
active involvement of the users are usually much less successful

\section{TRAINING AND VISIT APPROACH}

In the late seventies and early eighties, there was the introduction of the training and visit ( $T \& \mathrm{~V})$ system. This approach was utilized by extension service to involve farmers in the process of technology design and utilization. This approach was seen as a modification of the top-down transfer of technology model because there is room for feedback from the farmers. (see figure 1). The specific role of extension in this model is the provision of basic information, advisory and training, (Christoplos et al., 2001). It ensures that extension agents visit farmers regularly, transmit messages relevant to their production needs and identify problems faced by farmers which are quickly fed back to the scientists for solution or further investigation (Benor et al, 1984). This system which some researchers have adjudged to be practically effective is believed to facilitate research development through the extension workers and contact farmers who work with other farmers. The general expectation is that the Training \& Visit System has the ingredients to facilitate farmers' participation in research development through the feedback mechanism. However, some elements of rigidity are associated with it because farmers are generally seen as recipients of technology and not co-researchers in the development of the scientific methods and practices. Besides, the approach promoted the development of uniform recommendations, which largely disregarded the low-potential, highly diverse farming activities of resource-poor farmers, (Gitta, 2001)

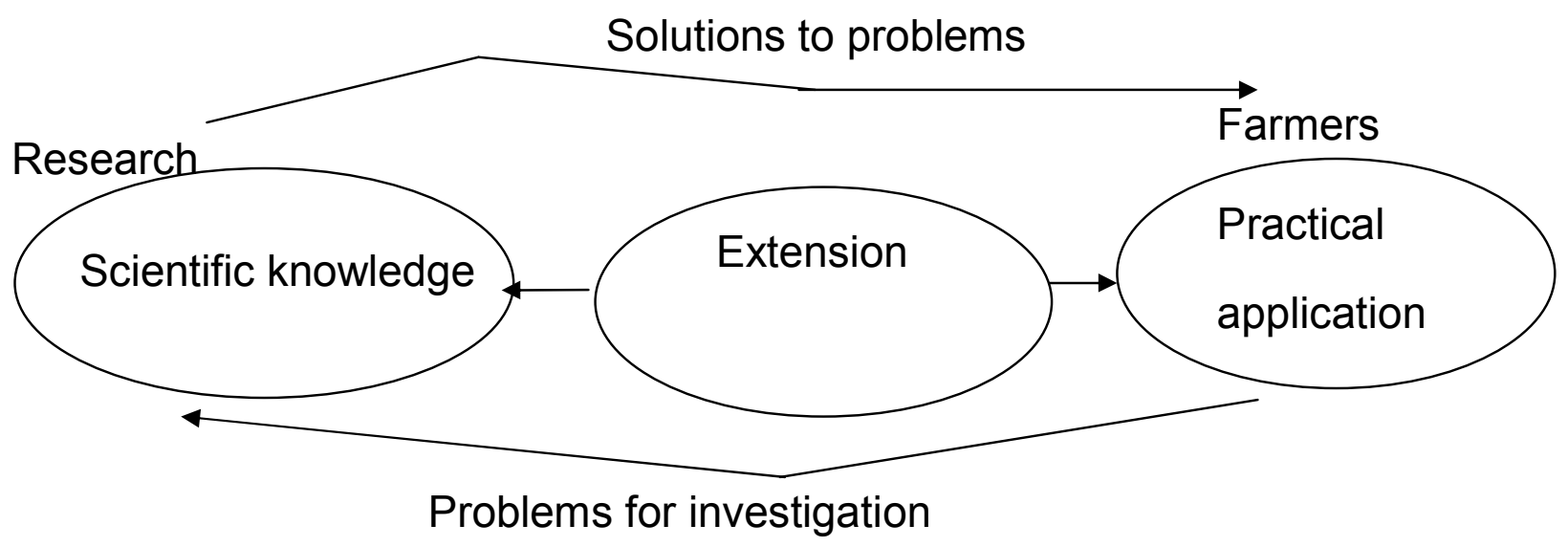

Figure 1: Research-extension-farmer linkage. Source: Author

The major criticisms with the $\mathrm{T} \& \mathrm{~V}$ model as it concern technology development and utilisation are that the model insufficiently adapt the general recommendations released from the research agencies to farm and farmer conditions. This in turn leads to low adoption levels, poor performance of technologies, as well as give too little interest in local knowledge and practices, cultural values and power relations within the recipient communities.

\section{FARMER FIRST (FF) APPROACH}

In the late eighties, there was the emergence of another paradigm known as Farmer-first with promotion of active participation, empowerment and poverty alleviation, (Chambers et al (1989, Gitta; (2001) This approach, identified the starting point of technology development to be active and equitable partnership between rural people as key partners with the researchers and the extension workers. Within this period, development practitioners have increasingly perceived farmers as key players and partners in technology development and transfer. This is based on the understanding that farmers have the capacity to collaborate as partners in the development of technologies (participatory technology development) and also have the capacity to diffuse new technologies among themselves (farmer-to-farmer approaches).
These insights culminated in what is now known as the Farmer First approach which involves some levels of participation (Chambers 1989 ; Hagmann, et al. 1998). The Farmer First approach argues that the strategy and methods of Transfer of Technology which have been adopted over the years, do not fit the resource-poor farming systems of indigenous agriculture, which is complex, diverse resource-poor and risk-prone (Chambers, Pacey \& Thrupp 1989), especially in SubSahara Africa. In contrast to technology-driven agriculture, with its standardizing package of practices, the farmer First approach stresses and recognises the abilities of the resource-poor farmers to experiment, adapt and innovate. Most importantly, the farmer first approach pays attention on the technical side of local knowledge system. However, this approach has been subjected to intense criticisms. Despite the emphasis on farmer participation and recognition given to farmers' indigenous knowledge, this approach has been accused of not address the issue of farmers active contribution in technology designed. The basic view underlying this criticisms lies on the fact that in most cases the technology development process still present a framework whereby technology is generated by researchers who indeed make all the major decisions. 
RELEVANCE OF INDIGENOUS KNOWLEDGE AND FARMERS PARTICIPATION IN TECHNOLOGY DEVELOPMENT.

In the past decades, scientists and researchers in the developed world cared little about the relevance of indigenous knowledge, even though it was reported that early efforts at agricultural technology generation were based on exploiting the knowledge of the best farmers and in promoting a process of horizontal transfers, i.e. farmer-to-farmer innovation. The prevailing attitude then was that the western science with its powerful analytical tool has nothing to learn from indigenous knowledge. Western scientists perceived indigenous knowledge as a social product closely linked or even restricted to a cultural and environmental content (Sabine and Rischksky, 2001)

However, the threat posed to humanity by ever increasing environmental degradation and the impacts of scientific technology on the population of developing countries have somewhat increased interest in indigenous knowledge. Some scientists are beginning to recognise that the world is losing an enormous amount of basic research materials as indigenous knowledge disappears and are now working towards promoting indigenous knowledge as a key to sustainable development. (Brokensha et al,1980). In recent times a wealth of information on indigenous knowledge pertaining to soils, plants, animals, and local people's innovative capabilities have been compiled.

Indigenous knowledge is seen as the cultural knowledge of rural people, promoting understanding and identity among members of a farming community, whose local technical knowledge and skills are inextricably linked to non-technical issues (Gitta 2001). Indigenous knowledge is native and unique to a group of people having some peculiarities in culture and tradition. In terms of the mode of acquisition, it is passed down from generation by oral/verbal (undocumented) communication. Apart from being the local technology base, it incorporates cultural, social and economic components of rural living. This mean that indigenous knowledge is dynamic, developing as collective experiences of specific social groups in interaction with their environment.

The place of indigenous knowledge systems in the overall agricultural production is very vital, but the vast store house of this knowledge system is yet to be explored and utilized in sustaining a reasonable level of development. Contrary to what may seem to imply or connote to researchers, there are a number of studies in the recent time that have highlighted the fact that local knowledge is not totally powerless in the face of outside knowledge(scientific knowledge) (Okali et al, 1994). The socio-economic appropriateness of indigenous knowledge in agriculture and years of experiences of farmers have produced successful techniques in mixed cropping patterns, water and soil management, seed selection, pest management, food processing and storage and other adaptations to the environment. (OTA, 1986). Therefore, a better understanding of indigenous farming system based on indigenous technical knowledge is considered essential for the successful development of new technology. Chambers
(1979) stated that one of the strongest contributions of indigenous knowledge to agricultural research is its systems of classification of biophysical environment. He however stated that indigenous knowledge is not meant to replace scientific knowledge but to complement it. Rather, there is much overlap between indigenous knowledge systems and scientific systems. Although some scholars have capitalized on the differentiated nature and structure of indigenous knowledge to question the value of ethno-scientific models, the fact remains that local farming practices and environmental knowledge can offer the starting points for developing farming methods which can increase the productivity and sustainability of local resources. In the light of farmers own experience and understanding, local farming knowledge can supply missing ecological links which may help scientists to develop alternative farming techniques. Many innovations either originate from farmers or are modified by farmers to adapt them better to their situation. In addition, it is recognized that farmers can play an important role in technology development dissemination and adoption through the integration of their knowledge system. Therefore, much effort should be tailored towards integrating indigenous knowledge system with the scientific knowledge system in designing and developing technology for successful adaptation and adoption.

Although, there is agreement among a wide variety of individuals on the need for farmer participation and integration of their knowledge system in research process, there is however no implicit statement or definition about the nature or level of their participation. Grumman (1993) noted that some approaches which incorporate farmers knowledge and participation in technology development process only focused on using farmers field and or using farmers to help researchers to identify the problems and set priorities during diagnostic survey but leaving them as recipient of the researchers products. Okali, et al (1994) reported the existence of wide differences in both opinion and practices on how local people should participate, for what purpose, at what stage and in what kinds of programmes. As the debate on local people's participation in research rages on, there are some basic questions to address the issue of farmers' participation in research and these include:

i) Why should small farmers participate in technology design and their knowledge system integrated in the process?

ii) What are the benefits, both expected and observed, of local people's participation and the use of their knowledge in technology development?

iii) At what level should local people participate and at what stages in technology design can they make inputs?

iv) How can farmers participation in technology process be enhanced, and what practical approaches and techniques should be developed and used to involve farmers in technology design?

In order to streamline the debate on the nature and level of participation of indigenous people in technology development, Bigg's (1989) developed a framework in which he described the relationship between research 
partners and the recognition given to local opinions and practices. In this framework, he classified participation in terms of levels of involvement of the people and the extent to which their knowledge, opinions and practices are given relevance in research activities, into four (4) categories namely: contractual, consultative, collaborative and collegiate. (see table 1).A thorough and careful examination of these categories reveal some critical issues as it concerns farmers knowledge integration and participation in technology development.

\section{CONTRACTURAL PARTICIPATION:}

Here, little interest is shown in farmers' knowledge. There is limited dialogue between the farmer and the scientists in the process of research. Farmers' role in this process is a passive one. He is involved in research as a collaborator with the scientists by contributing land and labour for on-farm trials often designed and managed entirely by researchers, who also derive conclusions from trials without attempting to interact with farmers about their responses to the technology. This approach is widely criticized because of its top-down nature as it depicted technology development process as moving technologies from experimental stations to farmers' fields.

\section{COLLABORATIVE PARTICIPATION:}

At these levels of participation, the scientists recognize the importance of local information and resources and hence adopt the diagnostic research approach which involves informal interactions between researchers and farmers to identify problems to be addressed in technology design. Farmers participate as informants and source of ideas for problem diagnosis. Scientists at this point collaborate with farmers in determining priorities among problems, as well as in the planning and designing of farming patterns suitable for a given farm environment.

\section{CONSULTATIVE PARTICIPATION:}

Although dialogue are done in coordination, action can however be taken independently by either party while individual agenda often dominate the relationship. The consultative and collaborative farmer participation widely given support by farming systems research have been identified with major short coming relating to the stage at which the involvement of farmers is activated. Also, the time-lag between identifying problems, designing potential technical solutions to farmers problem and obtaining farmers' reactions to developed technology during validation in farmer-implemented trials, can be prolonged..

\section{COLLEGIATE PARTICIPATION:}

The collegiate participation put emphasis on strengthening and providing support to informal research processes by building on existing skills and knowledge. The farmer who is seen as an active participant plays the role of a colleague in the research process. The researcher through his mutual learning work with the farmers, tap their knowledge about local conditions and innovations to discover new opportunities. In effect, the farmers take part in making decisions about the technology through participation in diagnosis, planning, design and experimentation.

Table 1.0: Categories Of Farmer Participation In Research Development Level Of Participation.

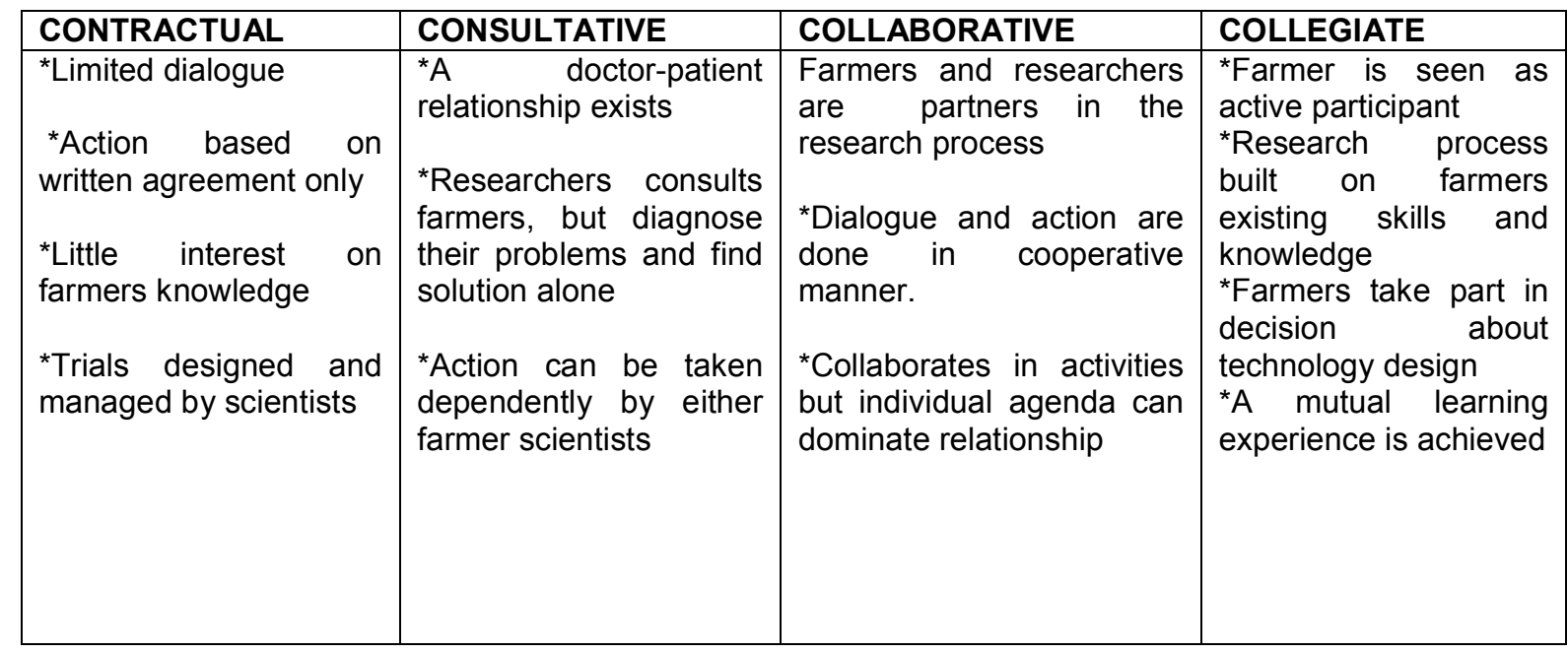

Source: Bigg's (1989) and Okali et al (1994) 


\section{A FRAMEWORK FOR USING INDIGENOUS KNOWLEDGE IN TECHNOLOGY DEVELOPMENT: FARMERS PARTICIPATION IN TECHNOLOGY}

There has been a radical rethinking of the role of farmers - and professionals in agricultural research and extension activities, which has led to a virtual revolution in the agricultural sector, which scholars have even termed it a 'paradigm shift' (Scoones and Thompson 1994). Having established the fact that the conventional approaches to technology development have not been attuned in developing countries like Nigeria in meeting farmers agricultural needs and having also noted that most recent practices and methods designed to facilitate farmers' participation in research development have not systematically involved local farmers as active participants in the planning, execution and evaluation of research, this paper therefore makes a case for Participatory approach in integrating farmers local knowledge and practical involvement in technology development (PTD). The PTD approaches are based on effective participation of rural communities. Farmers' participation in technology design has been seen as an integral part of agricultural research development. The focus of PTD is to promote greater involvement of farmers in rural in planning and implementing agricultural development activities, enhance capacity building, social mobilisation, experiential learning and empowerment which are major elements of the Participatory Technology Development approaches. In this model, farmers are encouraged to take initiative and work with research and extension staff on equal terms, for testing and implementing appropriate solutions.

Regardless of which name is used, participatory approach is essentially a process of purposeful and creative interaction between rural people and outside facilitators. Through this process, scientists and researchers try to increase their understanding of the main tracts of local farming systems, and based on ideas and experiences delivered from both local knowledge and modern science, the best options for addressing agricultural problems are selected and experimented on collectively,(See fig 2). This approach, which has the farmer as an active participant in research design, is ideal for the researcher in investigating ecological low-input and sustainable production system from the eye of the farmer who knows his needs and problems. The approach has been described as a people - centred process of purposeful and creative interplay between local people and communities on one hand and outsiders with formal scientific knowledge on the other. In order words, it provides an opportunity to build better linkage between various actors to increase learning from each other.

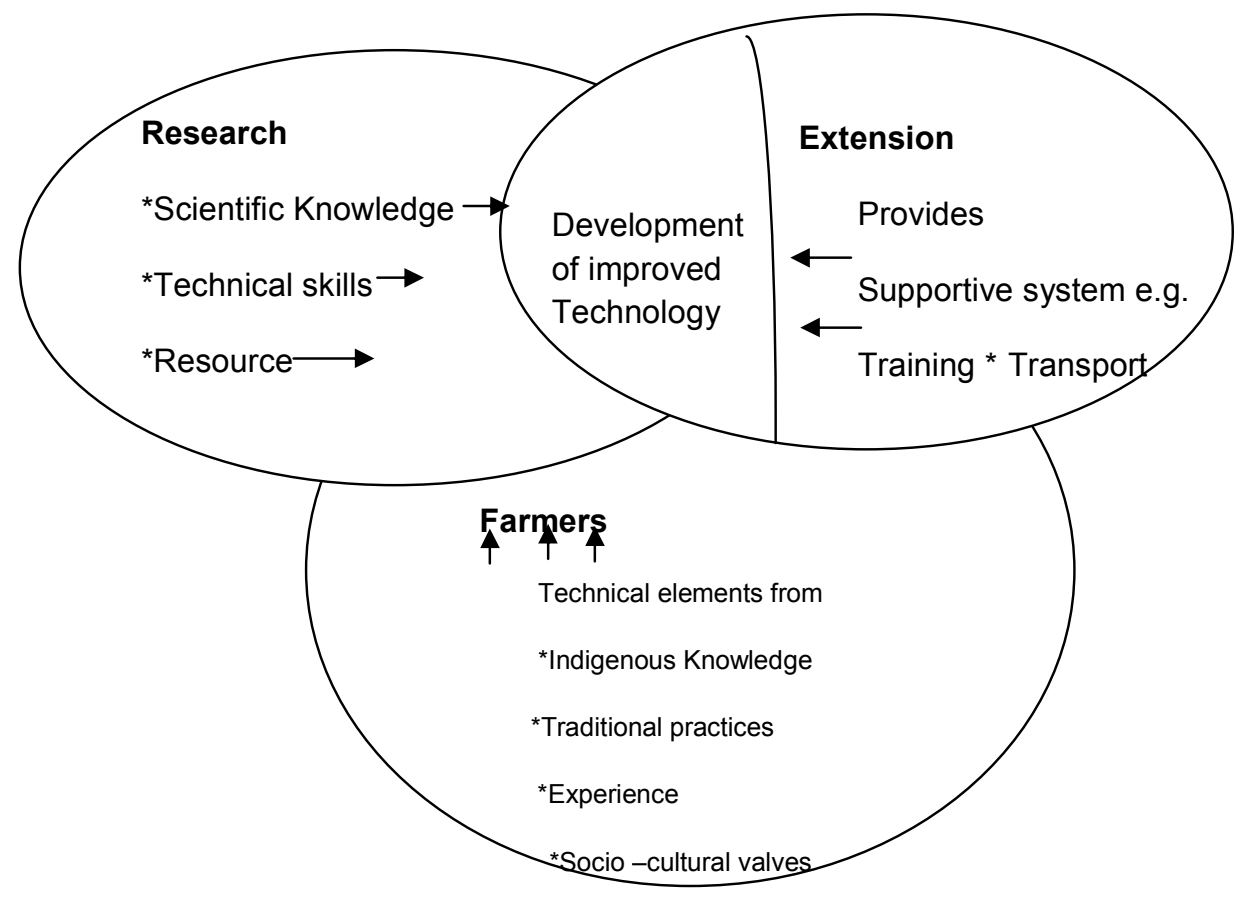

Source: Author's modification.

Fig. 2: Relationship between Scientists, extension personnel and farmers working together to develop technologies appropriate to famers and their environment. 
Participatory approach as a framework for enhancing the use of indigenous knowledge in technology development is anchored on two main assumptions:

'First, involving farmers in research design using participatory approach is based on the assumption that many farmers are actively engaged in an ongoing every day research for new or improved crop planting materials, varieties, production techniques, methods of protecting crops from pests and diseases and livelihood options. These farmers who have been referred to as 'research-minded' farmers by some writers are seen as generators of new information and in understanding the operations of technologies.

'The second assumption is based on the fact that there are core elements within local farming systems and the larger contexts within which they exist, which have not been observed or examined by formal research, but which are understood by farmers themselves, because of their years of exposure to them. In other words, there are hidden local resources, skills and knowledge which are yet to be exploited within the various local cultures. It is through a careful examination of these elements based on the knowledge and understanding of both farmers and scientists through participatory approach that sustainable technologies and solutions can be developed'.

Therefore, participatory approach unarguably is considered the most practicable and sustainable way in facilitating the use and the integration of indigenous knowledge into the process of technology development. It affords the different partners the opportunity to worked together in designing and refining technologies released to farmers for use and strengthens the existing experimental capacities of indigenous people (Essers. 1994, Jiggins 1992).In effect, farmers as "insiders" with their wealth of knowledge and practical abilities, interact with researchers and extension workers as the "outsiders" to identify, develop, test and apply new technologies and practices. Therefore, the participatory methodological process tends to reinforce the existing creativity of indigenous people and help them keep track with the process of generating innovations for sustainable use.

\section{IMPLICATIONS FOR THE ADOPTION OF PARTICIPATORY APPROACH TO FACILITATE THE USE OF INDIGENOUS KNOWLEDGE IN TECHNOLOGY DEVELOPMENT}

The inclusion of indigenous knowledge in rapid appraisal methodologies provides basis for the incorporation of local needs in technology development, this papers identifies potential implications in applying participatory approach to technology design, especially for agricultural development:

(i) Incorporating indigenous knowledge in technology planning allows scientists to understand how culture and beliefs interplay as major determinants to technology acceptance and utilization. But failure to recognize the importance of farmers' indigenous knowledge, may see scientists finding solutions for which there are no problems, since solutions can be best found within the framework of peoples own local knowledge system when recognized.

(ii) The integration of indigenous knowledge into technology development, using participatory approaches provide scientists, extension workers and the farmers the opportunity to work together on the same issue. Apart from exchanging knowledge and experiences with farmers, scientists reach some consensus with farmers on what is most needed. As a result of this collaboration, farmers become more confident that scientists and extension workers can help them without imposing their own knowledge or solutions to problems on them.

(iii) On the production of appropriate and acceptable technology, participatory approach is considered most appropriate, because it allows a research team to quickly and systematically collect information for the general analysis of a specific problem, need assessment or in identifying priorities for solution. As an approach which involves a working team of members who have different skills and background, it permits problems to be approached holistically in an informal and flexible manner. Here, learning takes place not just in the research station, but in the Farmers field where on-thespot assessment can be done.

(iv) Participatory approach is not only considered appropriate for working with the rural poor, but it is also seen to be essential for working in areas which might be considered inaccessible, difficult or out of touch for most researchers.

(v) Participatory approach can be tailored to fit the needs of almost any community in terms of both community dynamics and local preferences. It allows participants in research development to listen to the views of local people on different issues and learn their indigenous skills.

(vi) Participatory approach to technology development, enables scientists to understand the main characteristics and dynamics of agro-ecosystem within which a community operates, based on ideas and experiences derived from indigenous knowledge and informal science. Thus, scientists, in collaboration with farmers themselves can develop options that will meet the farmers' needs, thereby facilitate the use of indigenous knowledge as an integral part of technology development process.

(vii) Finally, participatory approach to technology development is a practical process that brings farmers knowledge and practical abilities to test technologies and also to interact with researchers as colleagues in identifying, developing, testing and apply new technologies and practices.

\section{CONCLUSION}

Cropping systems in most developing communities are considered to be more complex and diverse, hence requiring a system approach for both analysis and improvement. Thus, an alternative approach to the development of technologies that is able to cope with ecological uncertainty and diversity, and which also 
recognise and incorporate the input of indigenous people in designing practices is being called for. This call has become pertinent because many official systems which have implemented highly sophisticated models and approaches such as transfer of technology (TOT), Training and visit (T\&V), farming system research (FRS), etc toward technology generation and utilization, have not substantially improve food security or help to support sustainable farming practices). In addition, small scale farmers still have considerable information deficits on technical, economic, marketing and environmental issues, while many are unable to adapt the available stock of scientific knowledge to their farming environment because they are not economically feasible, socially acceptable and environmentally adapted. Giving the shortcomings of the conventional approach to technology development, a search for a more comprehensive approach which not only accommodate the local people but recognize the usefulness of their knowledge is inevitable. As indicated earlier on this paper, a wealth of information on indigenous knowledge pertaining to soils, plants and animals has been compiled by researchers. Also, literatures abound with examples of innovative discoveries of local people. It is therefore very important that scientists in Nigeria and other developing countries must give special considerations to the attributes of indigenous knowledge, built into the traditional practices in order to have sound technological base for future improvements needed for overcoming the often unpredicted food crisis prevalent in sub-Saharan Africa.

\section{REFERENCES}

Ajibade, L T. 1999 'Indigenous Approach to the control of Soil Erosion among small-scale farmers in Asa Local Government Area, Kwara State, Nigeria', The Nigeria Journal of Agriculture and Rural development JARD, 5(1) 20-29

Anon, 1998 'Learning together through participatory Extension', Department of Agricultural Technical and Extension Service AGRITEX Harare, Zimbabwe

Ashy, Jacquine A. 1998 'Small Farmer Participation in the Design of Technology , In Migguel, A.A and Hecht, S.B., Agro-ecology and Small Farm Settlement, Boca Raton, CBC pressi

Baker, D 1990 Re- orientation, not reversal: African farmer- based experience", Paper presented at Tenthannual Farming System Research/ Extension conferences, Eastlansing Michigan, Oct. 14-17, 1990.

Benor, D, J, C, Harrison and M. Baxter 1984 Agricultural Extension: the Training and Visit System, Washington D. C. The World Bank.

Biggs, S.D 1988 'Research- Poor farmer participation in Research: A synthesis of experiences from nine agricultural research systems'; COR Comparative study paper, New ISNAR
Brokensha, D Warren, D. M and Werner. O (eds) 1980 Indigenous Knowledge System and Development, New York University Press of America.

Chambers, R (ed) 1979 Rural Development: Whose Knowledge count? IDS Bulletin, Vol.10 (2)

Chambers; A Pacey and L. A Thrupp (eds) 1989)Farmer First; Farmer innovation and Agricultural Research, London: Intermediate Technology Publication.

Christoplos, I., J. Farrington and A.D. Kidd 2001. Extension, Poverty and Vulnerability: Inception report of a study for the Neuchatel Initiative. Working Paper No. 144. ODI, London

Essers, S P. 1994 Strengthening Farmers capacity for Technology Development, World Development 18(11) 1481-1499

Farrington, J. 1998. Organisational roles in farmer participatory research and extension: lessons from the last decade. Natural Resource Perspectives No. 27, January 1998. ODI, London. Downloadable from the ODI web-site

Gitta, Roth 2001 The position of Farmers local Knowledge within Agricultural Extension, Research and Development Cooperation", Indigenous Knowledge and Development Monitor Vol. 9 (3): 10-12

Grummen, A. L and A. Gupta 1993 'Documenting Farmers' Innovations", In How do People Survive through innovations inn Risky Regions, Unpublished paper, Ahmedabad Indian Institute of Management

Gupta, A. 1992 'Building upon peoples' Ecological Knowledge: Framework for Studying culturally embedded CPR Institutions', Ahmedab: Indian Institute of Management, Centrer for Management in Agriculture.

Hagmann, J. E. Chuma, M. Conolly and K. Murwira 1998. Client-driven change and institutional reform in agricultural extension: an action learning experience from Zimbabwe. Ag REN Network Paper No. 78. ODI, London.

Jiggins, J., 1992 Agricultural Technology: impact, issues and the action" In Gallin, R.S, M.A Amonoff and Ferugons (eds). The women and International Development Annual Vol.1, Boulder Co: West view press.

Kolawole, O. D 2001 'Local knowledge utilization and Sustainable Rural Development in the $21^{\text {st }}$ Century', Indigenous Knowledge and Development Monitor, Vol. 9 (3) 13-15. 
Office of Technology Assessment OTA 1986 Continuing the commitment: Agricultural Development on the Sahel: OTA-F-308, Washington D.C: OTA

Okali, C,.J. S Sumderg and J. Farrington 1994 Farmer Participatory Research: Rhetoric and Reality, London: Intermediate Technology Publication

Perrin, R. and D. Winkelmann 1976, Impediments to Technical Progress on small vesus Large Farms", American Journal of Agricultural Economics, 58: 888-894.

Philips, A .O and S. O Titilola 1995 Sustainable Development and Indigenous Knowledge Systems in Nigeria: The Role of the Nigeria Institute of Social and Research (NISER) in M. D Warren

Rajasekaran, B 1993 "Farmers Participatory Approaches to Integrate Indigenous Knowledge System and Research Station Technologies Towards Sustainable Food Products and Resource Conservation in India', Association for Farming System Research and Extension, 1318, Sept., Michigan State University, USA, PP175-179.

Roling, N. 1990. The Agricultural Research-Technology Transfer Interface: A Knowledge Systems Perspective. In: Kaimowitz, D. (ed.). Making the Link: Agricultural research and technology transfer in developing countries. ISNAR, The Hague, The Netherlands

Roling, N and E. Pretty 1995 "The Development of the concept of Agricultural Knowledge Information Systems (AKIS): Implication for Extension", Pp 125-138, In W. M Rivera and D. J Gustafson (eds), Agricultural Extension: Worldwide Institutional Evolution and Forces for Change", New York: Elservier Science Publishing Co.
Sabine, Homann and Barbara Rischkowoski 2001, "Integration of indigenous knowledge into landuse planning for the communal rangelands of Namibia" Indigenous Knowledge Monitor, vol. 19 (3) pp 6-9.

Titilola, S. T 2003 "Indigenous knowledge within the framework of Sustainable Agricultural Development in Nigeria", A lead paper at the indigenous knowledge and Agricultural conference, University of Agriculture, Makrudi, Benue State.

Tripp, Robert 1985 CIMMYT's experience with the Users perspective in Technology Development, In women and Agricultural technology: Relevance for research, New York: The Rockeffer Foundation.

Scoones, I. and J. Thompson 1994, Beyond farmer first. Rural people's knowledge, agricultural research and extension practice. London: Intermediate Technology Publications IIED.

Warren, D.M 1991, Using Indigenous Knowledge in Agricultural Development', World Bank Discussion Papers, Washington, D.C: he World Bank.

Warren, D.M, S. O. Titilola, and L. J. Slikkerver 1989 Indigenous Knowledge system: Implications for Agriculture and International Development" Studies in Technology and Social Change No.11, Ames, lowa: Technology and change Programme, lowa State University.

Warren, D.M; L.J Slikkerveer and D Brokensha 1995 The Cultural Dimension of Development of Indigenous Knowledge Systems, London: Intermediate Technology Publication 